\title{
Possibilities of the Subject 'Information and Communication Technologies' in Accustoming Primary School Students to Research Activities
}

\author{
https://doi.org/10.3991/ijim.v12i6.9622 \\ Sartayeva N. T. $\left.{ }^{\bowtie}\right)$, Kenesbaev S. M. \\ KazNPU named after Abay, Almaty, Kazakhstan \\ nazgul_88s@mail.ru \\ Zhailauova M.K. \\ KSU named after Korkyt Ata, Kazakhstan \\ Uaidullakyzy E., Nurzhanova S. A., Stambekova A. S. \\ KazNPU named after Abay, Almaty, Kazakhstan
}

\begin{abstract}
This article considers the issue of accustoming primary school students to research activities and basically focuses on information technology, which is the main tool for increasing cognitive activity. We define joint creative activities of teacher and student, which are carried out in seeking the solution of the unknown problem defined as an academic goal of students, and as a result of which cultural values are passed on as research activities. In this case, the teacher acts as the organiser of the forms and situations of research activity. It is insufficient for school children just to make a decision in solving the problems occurring in academic goals, the results achieved in the implementation process should be helpful for someone. From this point of view, the issue of molding a motivation, which permanently leads the student to master study-research skills, will be on the agenda.
\end{abstract}

Keywords - research, research activity, process, information and communication technology, learning and methodical complex

\section{Introduction}

There is a need to adapt school students to experimental activity from the primary classes to form a miscellaneous person who developed in line with the dynamic changes of the modern world.

It is obvious that aspiration to research studies gives an opportunity to change child's mental development into self-development process. In this regard, the main focus of educational and upbringing system is to teach children the new methods of any all mankind cultural actions with creativity and develop their ability to change the environment on the basis of their acquired knowledge. 
At the initial stage of the general academic school, it is necessary to organise the students' research activity in accordance with the true research logic. Under the guidance of the teacher, the student identifies the research problem and suggests the ways to solve them. It is an important task for a teacher to give a student an academic and research topic which will be relevant, interesting and important for the personal development of a young researcher. The research activity of the student in the educational process should be provided with auxiliary material and a set of equipment and the research tasks should make methodological support for the implementation of them at the child's discretion.

As a result of the analysis of the experiments in this area, it has been established that many research tasks are not aimed to develop student's personality by researching, but by solving problems of 'social importance' or 'topical matter for science'. These issues are often uninteresting and useless to a child, and of little value for society and science, too. In our opinion, this is because of the inability of a teacher to understand the difference between life and the learning process of a student. Furthermore, in our opinion, the greatest social importance is that the quest for a research arises from student's inner need. At the same time, the student must have a genuine cognitive interest in his research problem and the outcome must be important for the student [1].

The main issue is in choosing and defining the research theme with an agreement of the teacher. This way, the student's research activity achieves true results when the bilateral requirements correspond.

When considering the research problem, the correspondence of the relevance of the research with the age of the student is taken into consideration. It is obvious that it would be useless to force the students' mind to learn any abstract concepts. During the lesson, there is a need to arouse the necessity of researching and learning from aspiration to go thoroughly into the topic. Only in this case, the student's desire to research will develop from his inner thoughts. In other cases, during the creative process, the necessary actions are just formal, that is, the action of researching only outward aspect, but the student cannot ascertain the inner content. Therefore, the pedagogical outcome may not be considered [2].

The 'formula' of pedagogical cohesion is based on the subject-subjective didactic relationship. That is, both parties in the learning process still do not know the truths they are searching for on the topic because they are not accessible. However, the teacher as the supervisor takes responsibility for organising the didactic situation, which is necessary for the student to gain experience as a researcher. In the research process, the teacher must act as a co-researcher in the heuristic interview but not as a person who knows everything but conceals it.

Once organised, the teacher will help each student to find their way of research individually and will support, consult and assist in achieving the results. If the teacher notices that his student makes the wrong decision, he must not stop his actions immediately. The teacher should explain with insight to the student that he is going astray by speaking to him in private. The complexity and importance of the leading role for the teacher are in monitoring, managing and consulting in time.

Scholars should prepare for teachers didactic tools and their order and system, and provide with them in time. Only this kind of cognitive logic can set a straight line 
forward by the way of development. We should give much prominence to the fact that if one of the elements of the chain of this cognitive process stops or changes; it will have a negative impact on a child [3].

Each student's reflexive abilities arise from internal necessity during the individual implementation of research action, and he is motivated to take on 'discoveries' which were made under the guidance of the teacher. It leads him to clearly identify the problem of research, to compare the information he has gathered, to choose intuitively which one can lead to an effective way and during studying of different subjects, it forms the practice of using all acquired knowledge, ability and skills at the interdisciplinary level.

Students master the heuristic method of education; become the subject who acquired research competence. In the mind of the student who has mastered one 'cell' of such an effective and powerful scientific-creative process will develop 'new cognitive generation'.

During the involvement of students in research activities, the teacher puts forward the issue of organising of a single research task solution, taking into account students' research experience at different levels. The most important point of the didactic issues is that the teacher prepares in advance for students effective methods and several ways of achieving a result, and renders it by giving a short explanation. Students should choose from them the methods and forms of work that will enrich their own research experiences. The teacher also gives advice and supervises him. The chain of stages of joint actions of teacher and student is an integral part of research action. Consequently, the research competence created as a result of such adaptation will lead to the emergence and formation of other competences.

In a thorough consideration of the problem of creating research processes, it is important to emphasise that the following is important for organising this process and achieving good results:

- First of all, it is important to take into account both the student's and teacher's interests in choosing the research theme;

- Secondly, it is important that the teacher understands the core of an issue;

- It is important to organise and conduct collaborative work which is aimed at solving the research problem through the mutual responsibility and assistance of the teacher and pupil;

- It is important that students take initiative through self-development during the research process until which the unknown problem is identified in various joint intellectual, communicative and creative areas;

- It is important that a teacher in solving the problem at a creative level adds any discovery for the student, and then only for science (this is optional) [4].

This analysis leads to a final serious conclusion. In particular, the genuine interest of students is an important factor that makes teaching more effective and successful. This is a great opportunity that teachers and pedagogues can achieve. However, it is obvious that there is a shortage of primary schooling because current social resources have not passed didactic adaptations. That is why the lack of resources and the peculiarity of domestic pedagogy are the most critical factor when it can be aimed at meaningless struggle with the student's normal interest and necessity $[5,13]$. 
One of the stages of accustoming primary school students to research activities is organising the training which introduces research techniques for each child in the classroom. The teacher's task here is to help children to understand the idea that 'the choice of method depends on a person's genuine opportunities'. Once they have identified the sequence of work, they will begin to gather information on this topic. But it's hard to remember or write down that information because writing skills have not yet been developed. Therefore, it is preferable to make graphic images. The child's ability to make notes and put marks reflects his level of development of associative thinking and creative ability.

Starting from the second grade, there will be implemented works aimed at developing child's abilities to see the problem, ask questions, make assumptions, define the concepts, control and make experiments, make conclusions, structure information, etc. For this, giving following activities is approved:

- continue the unfinished conversation;

- talk on behalf of another character;

- describe 1 day of your dream life;

- find out how many meanings this thing have; (explain the possible ways of use of any object);

- name as much as possible features of the object $[6,14]$.

Taking into account the fact that there is a large amount of information before accustoming a student to research action, the student is given directions as 'Thinking', 'Asking others', 'Controlling', 'Watching from TV', 'Getting information from the Internet' and 'Making experiments' by distributing illustrative papers. The student's informational culture is recognised by any kind of information, including textual, audio, graphic and other types of motivation and operational readiness. It is important that teachers remind learners each lesson that the research action for the student is the opportunity to demonstrate his creative potential as much as possible $[7,8]$.

Describing the contents of the works of accustoming students to research activities by teaching information and communication technologies in primary classes, the following features of the process were identified as the key one.

1. The works of accustoming students to research activities depend on the nature of the relationship between the teacher and the pupil. This relationship can only have a positive effect if there is a positive mutual understanding and respect.

2. In their professional activities, a teacher should take into account the controversial characteristics of the cognitive process. The controversial process of cognition is a contradiction between the personal experience and the acquired knowledge for students. This controversy is a prerequisite for a problematic situation, which is a condition for performing research activities based on cognitive action.

3. In order to encourage students to engage in research, the teacher should focus on cognitive interest. As an external motivator for research activity, cognitive interest is a powerful tool for the development of cognitive activity. It depends on the teacher's skills to make cognitive interest as a personally important and continuous action. 
4. An important pedagogical condition for accustoming students to research activities is to engage students independently in work. It is important to turn it into purposefully and consistently characterised action by teaching them independently. The independent work will enable students to identify the problem and find the optimal ways to solve the problematic situation.

5. The content of the training material also reflects the set of pedagogical conditions for accustoming primary school students to research action.

Exactly this content is one of the leading motives of student's research actions. When preparing the training material, it is important to take into account its perspective, experimental value, personal importance and relevance.

\section{Materials and methods}

The pedagogical experiment of the research was carried out at No 2 schoolgymnasium 'Murager' for gifted children where lessons are conducted in three languages and at No 217 general academic school named after B. Shalgynbayev in Kyzylorda in 2015-2018. The research process of the pedagogical experiment, including three stages, involved 72 primary school students, 25 school teachers and 20 representatives of school principals.

The analysis of the outcome of experiments revealed that the involvement of primary school students in research activities was not adequate at the expense of various barriers.

The questionnaire such as: 'What is the main obstacle for primary school students to be engaged in research activities systematically'? and sample answers were given to school principals, primary school teachers and primary school students who were involved in the identification phase of the pedagogical experiment. Learners were required to mark the answers. Along with primary school students, teachers, school principals' 'palettes' responses, in the long run, unfortunately, have shown that primary school students are still unaware of research activity.

According to the survey, $100 \%$ of school principals say that they could not find a school teacher who will be engaged in research, because it is not specifically mandated in the curriculum, and it proves that primary school teacher cannot choose this way as an effective to develop student.

And, as teachers are not equipped with methodological support and are not fully provided with didactic tools, we have to keep in mind that they do not pay attention to it to prevent any extra problems.

According to the diagram in Figure 1, in general academic schools, the vast majority (97.2) of reasons for the lack of research activities among primary school students is due to the lack of the required skills. 


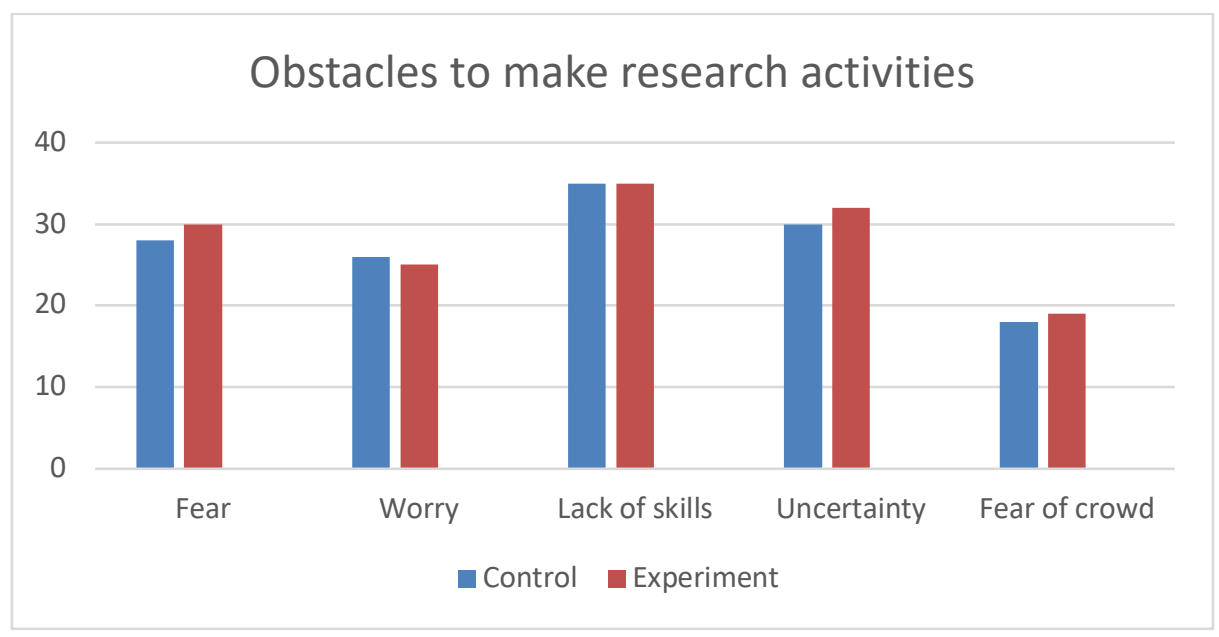

Fig. 1. Factors that interfere with the research activity were identified as a result of the survey

During the identifying phase of the pedagogical experiment, 'Testing of Motivational Environment of Learners' test was presented to determine the direction of the motivation of students in primary classes. Based on the methodology proposed by M. V. Matyukhina, we will be able to identify the leading motives of the motivation environment of primary class students. All the motives listed in this technique can be classified as follows:

- broad social motivation, i.e., duty and responsibility, self-determination and selfrealisation motives;

- narrow personal motivation, i.e., motivation to succeed, motivation to gain reputation;

- educational and cognitive motivation in relation to the content and teaching process;

- motivation to escape from failure.

As a result, most primary school students chose reputation and social motivation. This shows that students would like to have a good image in the classroom and in front of their parents and teachers. The motive 'escape from failure' is above 60 , because they are afraid of failure and society's wrong perception, the opinions of other people matter more than their own opinion. Therefore, it is essential to encourage a student to reach the level of the individual person from the earliest age [16].

The training-forming stage of the pedagogical experiment was conducted in three classes of the above-mentioned schools. The learning-didactic material used in the training-forming experiment is a new educational-methodical complex for the thirdgrade general academic school students, called 'Information and communication technologies' and the system of tasks for the development and motivation of additional research activities. 


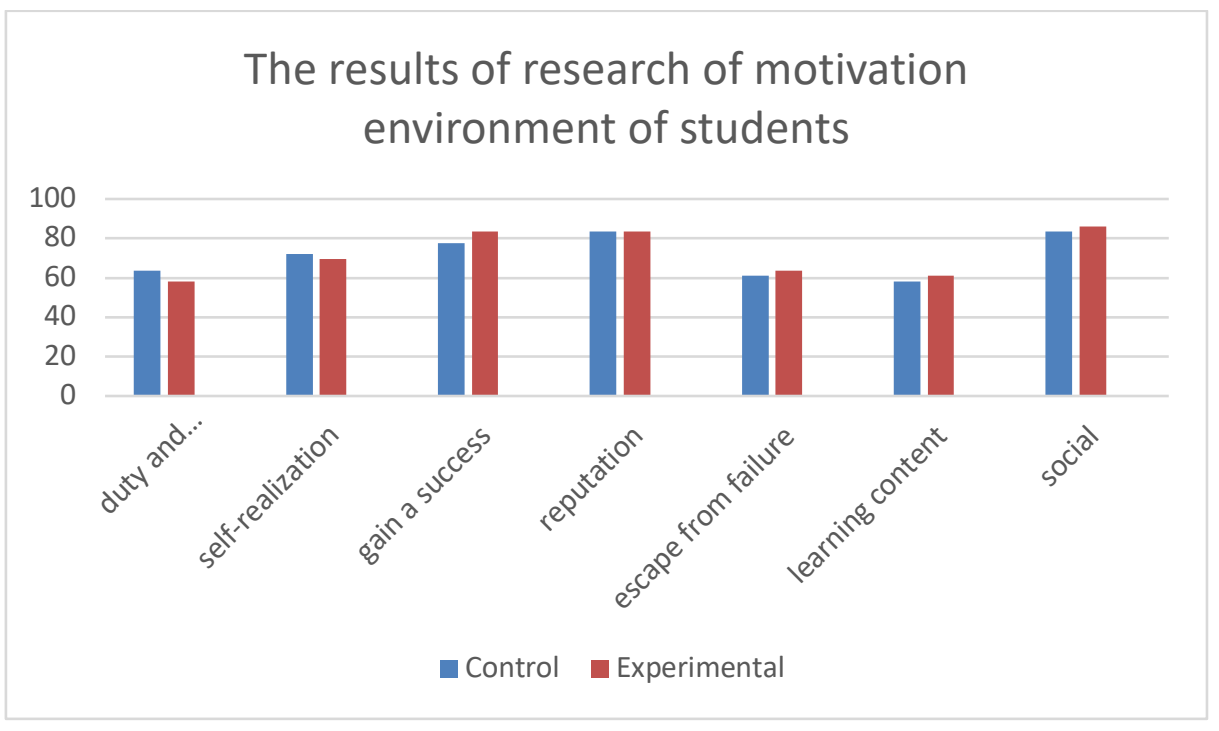

Fig. 2. The results of Matyukhin's test.

In accordance with the above content, the book 'Information and communication technology' and the three chapters of the research activities presented in the workbook and the complexity level of tasks were taken into account. The structure of tasks for developing motivation of the research activity of primary school students was grouped according to their content and objectives as follows:

These are analytical, problematic, stimulating-motivational, project and evaluative tasks [9, 17]. Each new topic presented in the textbook 'Information and Communication Technologies' starts with the leading question or task of the character 'Zerde'.

This allows the student to act independently and to create a product himself. As a result of answering the question and implementing the task, the theme of the new lesson is identified. That is to say, Zerde boosts students' interest and introduces a new topic. One more aspect mentioned by the authors is that, as the learning subject was a new subject, we have tried to use illustrations and graphic images to explain the teaching material easily.

In the educational-methodological complex, the following tasks were given to encourage the research activity:

1. Determine what items are included in the Microsoft PowerPoint program window.

2. Find out which programs can be used for typing, cutting and copying. Write your answer on the answer line.

3. Using the Internet, search for information about the national holiday of the country and discuss with your neighbour how to include the information in the presentation.

4. Who do you think who often makes the sound recording and editing? Why?

5. Is it possible to use a colour palette in a graphic editor for photos that are embedded on a specific theme? Why? 
6. How do you think about how to combine the following parts to make one video? Maybe there's another way to combine?

7. We can see that several font types were used in the notebook's cover. What other documents do you know in which several types of fonts were used? Give an example [10].

8. Read third letters of each given word together, write the definition for that word by yourself. Model: Amount $-\mathrm{m}$, Program $-\mathrm{o}$, sled $-\mathrm{n}$, Aliya $-\mathrm{i}$, environment- $\mathrm{t}$, old man - r. The word 'monitor' is taken from the third letters of these words. Monitor is a computer's input device. Honour, desire, lesson, intelligence, make, Olzhas, flame, clean, cord.

9. Search for the interesting information about celebrities in the presented portraits from the Internet and collect them and make reference.

10. Prepare interview questions on the topic 'What sounds can be heard at school'? Chat with your friend.

11. Explore the Demo tab on the PowerPoint program menu. Write about what you can do there.

12. Build your own keyboard by grouping symbols that are not on the keyboard with the group.

13. What objects show in daily life the figures on the graphic editor?

14. In what additional applications, figures on the graphic editor can be used?

15. In your opinion, how important is the sound recorder's role in the work and learning process of a person? How do you think the sound recording programs are mostly important in which specialists' professional life? Give examples. Make conclusion [11].

16. Is there a similarity between the computer and other technical equipment (television, telephone and camera)? Research it out.

17. Build a dialogue between the computer and its devices.

18. One of the computer devices is the mouse. This is also called mice. Why this device is called so?

19. Explore the table and schedule the menus and their functions in the Windows program.

20. Research the origin of the term 'Program'.

21. Collect historical Information called 'Baikonur Cosmic Baikal' according to the 'Spiritual Modernisation' program. Make a slideshow and short statement using textual information from Word.

22. Carry out 'Our Class' project. Make a slideshow [11].

The control experiment was carried out at the end of the academic year in the control and experimental classes. Learners were provided with part-time tasks and tested how well their research skills were developed. Tasks during the control period were now grouped into reproductive, reflexive, creative-creative ones, according to their control objectives. Based on the analysis of the performed tasks, the following results were obtained. 
Paper-Possibilities of the Subject 'Information and Communication Technologies' in Accustoming ..

Table 1. To check the level of formation of research skills of students during the control stage

\begin{tabular}{|l|c|c|c|c|}
\hline \multirow{2}{*}{\multicolumn{2}{|c}{ Tasks }} & \multicolumn{2}{c|}{ The participants of the control stage of the experiment } \\
\cline { 2 - 5 } & \multicolumn{2}{c|}{ Control group-36 } & \multicolumn{2}{c|}{ Control group-36 } \\
\cline { 2 - 5 } & Number & $\%$ & Number & $\%$ \\
\hline Reproductive task & 32 & 88.8 & 28 & 77.7 \\
\hline Searching task & 15 & 41.6 & 35 & 97.2 \\
\hline $\begin{array}{l}\text { Research task. To check theoretical } \\
\text { knowledge. }\end{array}$ & 10 & 27.7 & 32 & 88.8 \\
\hline Research task. To check cognitive interest. & 18 & 49.9 & 35 & 97.2 \\
\hline Reproductive task & 32 & 88.8 & 28 & 77.7 \\
\hline
\end{tabular}

As the experimental team was taught by the methodological system and the development of motivation for research was aimed, we see that the results are very good.

The next task that was carried out during the control stage was developed according to the Bloom Taxonomy, and the results of the implementation at those levels were checked.

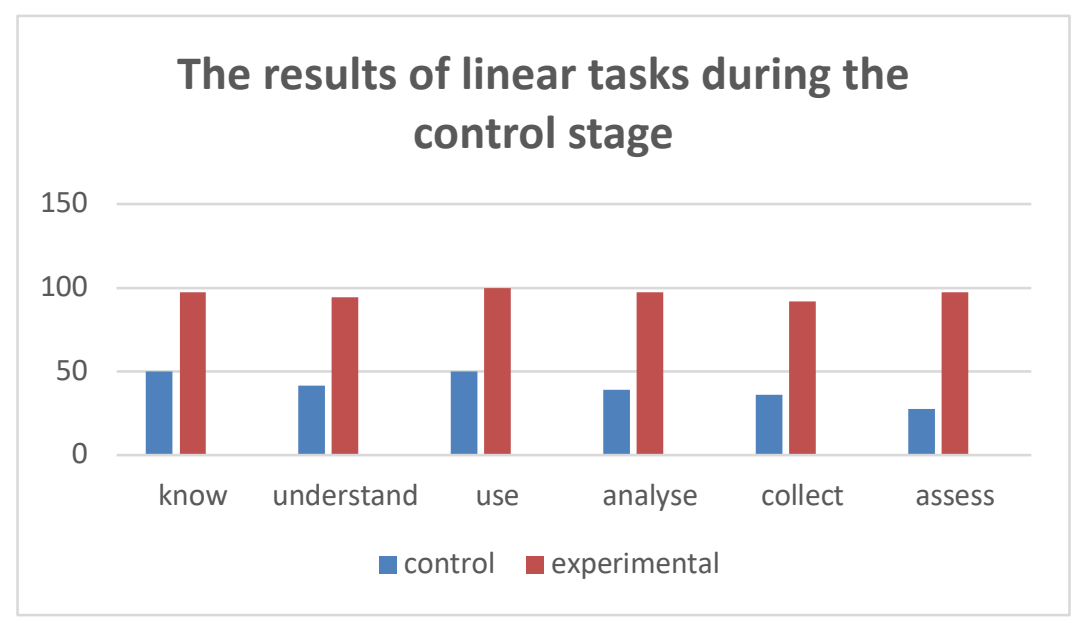

Fig. 3. Relative indicator of the formation of students' skills according to the Bloom taxonomy

Thus, according to the results of the third control stage of the pedagogical experiment, the model theoretical-methodological basis of which was suggested and on the basis of which was made, the specific methodical system achieved its goals. This was proved that only after preparing a special educational and methodical complex, developing a system of special research assignments, developing a system of out-of-class work and training teachers and students for the pedagogical experiment, there can be achieved good results. 


\section{Conclusion}

Current information about teaching the subject 'Information and Communication Technologies' in the third grade of primary schools identified that there is no methodology on the issue of formation of research action motivation of these students, the practical part of which is complete and the theoretical base of which is reasonable. This argument revealed the necessity to make a methodology for developing students' research activity motivation during teaching information technology in the third grade of primary school.

A special learning-methodical complex called 'Information and communication technologies', which includes textbooks, workbooks and tutorials for teachers, has been developed for the teaching of the subject 'Information and communication technologies' for the third grade of primary schools $[9,10,11,15]$.

In the third grade of primary school, the necessity to develop a methodology for the formation of students' research activity motivation while teaching the subject 'Information and Communication Technologies', first of all, necessity of grounding theoretical standpoint of the methodology in a broadway was identified, and this task was resolved at an expected level. The psychological and pedagogical peculiarities of the use of information technology in primary school were recognised, and a reliable methodology for forming the research activity motivation of the third-grade students by those theoretical foundations have been developed.

The effectiveness and utility of the methodological system which was suggested in developing research activity motivation for the third-grade students of primary schools by using information and communication technology was proved by specially organised pedagogical experiment. Specially developed and experimentally proven methodology can be used as a rational practice for Kazakhstani schools to develop the motivation of third-graders in teaching ICT.

Primary school students not only know the ways to use computers, the Internet, other types of information technology but also have a flexible systematic approach to achieve qualitative results by performing research activities in the forefront of working with them, with the possibility of continually updating the task patterns, theoretical and practical aspects of developing students' motivation to carry out research activities independently. It follows an open systematic approach [12].

During the research, the aim of the research was achieved and the research objectives were solved. This hypothesis not only laid the foundation for proving the effectiveness of the teaching-methodical complex and the methodology of its use in the real pedagogical process but also proved that the proposed model is an open system and that its composition can be filled with discoveries.

\section{$4 \quad$ References}

[1] Slobodchikov, V. I. (2006). The understanding of research work in psychology of education. Research Work of School Students, 34-38. 
[2] Leontovich, A. V. (1999). Learning-research activity of school student as a model of pedagogical technology. National Education, 10.

[3] Rasskazova, Z. V. (2014). Research activity of primary school students asa component of learning process in conditions of general academic oraganizations. Young Researcher, 4:S1080-S1082.

[4] Obukhov, A. S. (2008). The problem of assessment of the quality of education. Research Work of School Students, 2:S17-S23.

[5] Goldsteen, M. \& Goldstein, I. (1985). How we recognize?

[6] Sartayeva, N. T. (2016). Conducting research activities in primary school. The International Scientific Journal "Young Scientist"-Kazan, 5.2(109.2):53-56.

[7] Savenkov, A. I. (2007). Psychological bases of research teaching of school students. Physics: Problems of Research, 3:S14-S24.

[8] Leontovich, A. B. (1999). Learning-research activity of school student as a model of pedagogical technology. National Education.

[9] Kenesbayev, S. M., Oralbekova, A. K., Sartayeva, N. T. \& Danabayeva, M. (2017). Information and communication technologies. Textbook for 3 rd grade of general academic school (Trial version) (114 p). Almaty, Kazakhstan: Atamura.

[10] Oralbekova, A. K., Sartaeva, N. T. \& Danabayeva, M. A. (2017). Information and communication technologies. Workbook. For the 3rd grade of the general academic school (Trial version) (64 p). Almaty, Kazakhstan: Atamura.

[11] Sartayeva, N. T., Oralbekova, A. K. \& Danabayeva, M. A. (2017) Information and communication technologies. Methodical instruction for teachers of the 3rd grade students of generalacademic school (Trial version) (176 p). Almaty, Kazakhstan: Atamura.

[12] Sartayeva, N. T. (2016). Research activity of primary school pupils is the main way to scientific knowledge. Pavlodar State University named after S. Toraigyrov "Khabarshysy," 2:216-221.

[13] Prasertcharoensuk, T. \& Tapkhwa, N. (2016). Schools, parents, and community partnership enhancing students' learning achievement. Contemporary Educational Researches Journal, 6(1):30-39.

[14] Coklar, A. N. \& Akcay, A. (2018). Evaluating programming self-efficacy in the context of inquiry skills and problem-solving skills: a perspective from teacher education. World Journal on Educational Technology: Current Issues, 10(3):153-164.

[15] Uhlirova, M. (2018). Semantic space of elementary teacher attitudes towards computer teaching assistant. Global Journal of Information Technology: Emerging Technologies, $8(1): 1-9$.

[16] Almeida, F. \& Castelo, D. (2018). A technological platform for the creation and evaluation of psycho-technical tests. Global Journal of Computer Sciences: Theory and Research, 8(1):53-61.

[17] Nawaila, M., Kanbul, S. \& Uzunboylu, H. (2018). Toward making social media effective in our classrooms: a 9-point method. International Journal of Interactive Mobile Technologies (iJIM), 12(4):59-71.

\section{Authors}

Sartayeva N. T. is PhD Doctoral Student at KazNPU named after Abay, Almaty, Kazakhstan (nazgul_88s@mail.ru).

Kenesbaev S. M., Doctor of Pedagogical Sciences, is Professor at KazNPU named after Abay, Almaty, Kazakhstan (kenesbayev_sm@mail.ru). 
Paper-Possibilities of the Subject 'Information and Communication Technologies' in Accustoming ..

Zhailauova M.K., Candidate of pedagogical sciences, is associate professor at KSU named after Korkyt Ata (mzhailauova@mail.ru).

Uaidullakyzy E., PhD, is Senior Teacher at KazNPU named after Abay, Almaty, Kazakhstan(elmira_uaidulla@mail.ru).

Nurzhanova S. A. and Stambekova A. S., Candidates of Pedagogical Sciences, are Senior Teachers of KazNPU named after Abay, Almaty, Kazakhstan (sajila@mail.ru)

Article submitted 01 September 2018. Resubmitted 17 September 2018. Final acceptance 01 October 2018. Final version published as submitted by the authors. 